\title{
Lesion preparation with cutting balloon angioplasty is associated with coronary aneurysm formation in polylactide bioresorbable vascular scaffold implantation
}

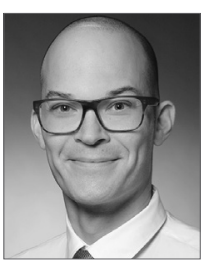

Dennis Rottländer, MD; Thorsten Schneider, MD; Hubertus Degen, MD; Michael Haude*, MD

Department of Cardiology, Städtische Kliniken Neuss, Neuss, Germany

\section{Introduction}

Cutting balloon angioplasty (CBA) is predominantly used for preparation of difficult lesions. Recent reports describe the use of cutting balloons also prior to implantation of bioresorbable vascular scaffolds (BVS) ${ }^{1}$. As vascular injury and pathological vessel healing might play a key role in the pathology of peri-interventional evagination or aneurysm formation ${ }^{2}$, we hypothesised that aggressive lesion preparation leads to coronary artery injury resulting in vessel dilatation. We therefore aimed to investigate the incidence of coronary aneurysms after BVS implantation and to assess the safety of lesion preparation with CBA.

\section{Methods}

This retrospective analysis comprises consecutive patients with BVS implantation in 2013 and 2014 and six-month angiographic follow-up. All patients who underwent predilatation prior to BVS implantation using the Flextome ${ }^{\mathrm{TM}}$ Cutting Balloon ${ }^{\mathrm{TM}}$ Dilatation Device (Boston Scientific, Marlborough, MA, USA) were assigned to the CBA group, whereas all patients treated with conventional balloon angioplasty alone were allocated to the conventional BVS group. Two independent experienced interventional cardiologists blinded to the operator performed quantitative coronary angiography (QCA) assessments (Philips, Amsterdam, the Netherlands). Coronary aneurysm was defined as a dilatation of $>1.5$ times the reference vessel diameter (RVD).

Statistical analysis was performed using PASW Statistics 18 software (SPSS Inc., Chicago, IL, USA). Differences were evaluated by chi-square test for discrete variables and Student's t-test for continuous variables. For ordinal data, the Mann-Whitney U test was used. A p-value $<0.05$ was considered statistically significant.

\section{Results}

Seventy-two patients with BVS implantation and six-month follow-up QCA were enrolled in this retrospective study. Thirteen patients $(18.1 \%)$ underwent CBA. Table 1 shows the patients and procedural characteristics. In the conventional BVS group, 23 patients were implanted with the metal Magmaris scaffold (formerly called DREAMS 2G; Biotronik AG, Bülach, Switzerland), and 15 and 21 with the polymeric DESolve ${ }^{\circledR}$ (Elixir Medical

*Corresponding author: Department of Cardiology, Städtische Kliniken Neuss, Preussenstr. 84, 41464 Neuss, Germany. 
Table 1. Patient and procedural characteristics.

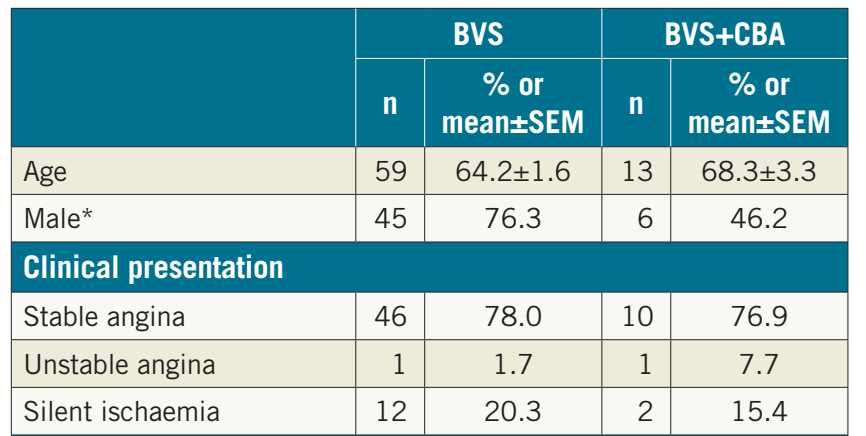

\section{Site of lesion}

\begin{tabular}{|l|c|c|c|c|}
\hline $\begin{array}{l}\text { Left anterior descending } \\
\text { (LAD) }\end{array}$ & 23 & 39.0 & 8 & 61.5 \\
\hline Left circumflex (LCX) & 14 & 23.7 & 3 & 23.1 \\
\hline Right coronary artery (RCA) & 22 & 37.3 & 2 & 15.4 \\
\hline
\end{tabular}

\section{Lesion characteristics}

\begin{tabular}{|c|c|c|c|c|}
\hline Lesion length (mm) & 59 & $13.2 \pm 0.8$ & 13 & $14.6 \pm 1.8$ \\
\hline $\begin{array}{l}\text { Reference vessel } \\
\text { diameter }(\mathrm{mm})\end{array}$ & 59 & $2.9 \pm 0.4$ & 13 & $3.0 \pm 0.2$ \\
\hline Type B2/C & 11 & 18.6 & 3 & 23.1 \\
\hline \multicolumn{5}{|c|}{ Level of calcification } \\
\hline None & 9 & 15.3 & 3 & 23.1 \\
\hline Mild & 19 & 32.2 & 4 & 30.8 \\
\hline Moderate & 23 & 39.0 & 5 & 38.5 \\
\hline Severe & 8 & 13.6 & 1 & 7.7 \\
\hline
\end{tabular}

\begin{tabular}{|c|c|c|c|c|}
\hline \multicolumn{5}{|l|}{ Predilatation } \\
\hline Balloon size, mm & 59 & 2. $9 \pm 0.5$ & 11 & $3.4 \pm 0.1$ \\
\hline Balloon pressure, atm & 59 & $17.1 \pm 0.4$ & 11 & $16.0 \pm 0.6$ \\
\hline Balloon length, mm & 59 & $14.1 \pm 0.5$ & 11 & $14.7 \pm 1.2$ \\
\hline Balloon-to-artery ratio & 59 & $0.97 \pm 0.1$ & 11 & $1.03 \pm 0.2$ \\
\hline \multicolumn{5}{|l|}{ Cutting balloon } \\
\hline $\begin{array}{l}\text { Cutting balloon } \\
\text { diameter, mm }\end{array}$ & & & 13 & $3.0 \pm 0.4$ \\
\hline $\begin{array}{l}\text { Cutting balloon } \\
\text { pressure, atm }\end{array}$ & & & 13 & $16.6 \pm 0.9$ \\
\hline $\begin{array}{l}\text { Periprocedural } \\
\text { extensive dissection }\end{array}$ & 3 & 5.1 & 2 & 15.4 \\
\hline
\end{tabular}

\section{BVS}

\begin{tabular}{|l|c|c|c|c|}
\hline Scaffold diameter, $\mathrm{mm}$ & 59 & $3.1 \pm 0.1$ & 13 & $3.2 \pm 0.1$ \\
\hline Scaffold length, $\mathrm{mm}$ & 59 & $21.3 \pm 0.5$ & 13 & $21.7 \pm 0.8$ \\
\hline Coronary imaging \\
\hline IVUS & 26 & 44.1 & 6 & 46.2 \\
\hline OCT & 25 & 42.4 & 3 & 23.1 \\
\hline
\end{tabular}

\begin{tabular}{|l|c|c|c|c|}
\hline Post-dilatation \\
\hline Non-compliant balloon & 51 & 86.4 & 12 & 92.3 \\
\hline Balloon size, mm & 51 & $3.3 \pm 0.5$ & 12 & $3.4 \pm 0.2$ \\
\hline Balloon pressure, atm & 51 & $17.3 \pm 0.5$ & 12 & $16.0 \pm 0.6$ \\
\hline Balloon length, mm & 51 & $16.4 \pm 0.7$ & 12 & $16.2 \pm 1.3$ \\
\hline Balloon-to-artery ratio & 51 & $1.09 \pm 0.1$ & 12 & $1.12 \pm 0.3$ \\
\hline $\begin{array}{l}\text { * } p<0.05 . \text { BVS: bioresorbable vascular scaffold; CBA: cutting balloon } \\
\text { angioplasty; IVUS: intravascular ultrasound; OCT: optical coherence } \\
\text { tomography; SEM: standard error of the mean }\end{array}$ \\
\hline
\end{tabular}

Corporation, Milpitas, CA, USA), and Absorb (Abbott Vascular, Santa Clara, CA, USA) scaffolds, respectively; in the CBA group three patients were implanted with Magmaris, five with DESolve and five with Absorb (Figure 1).
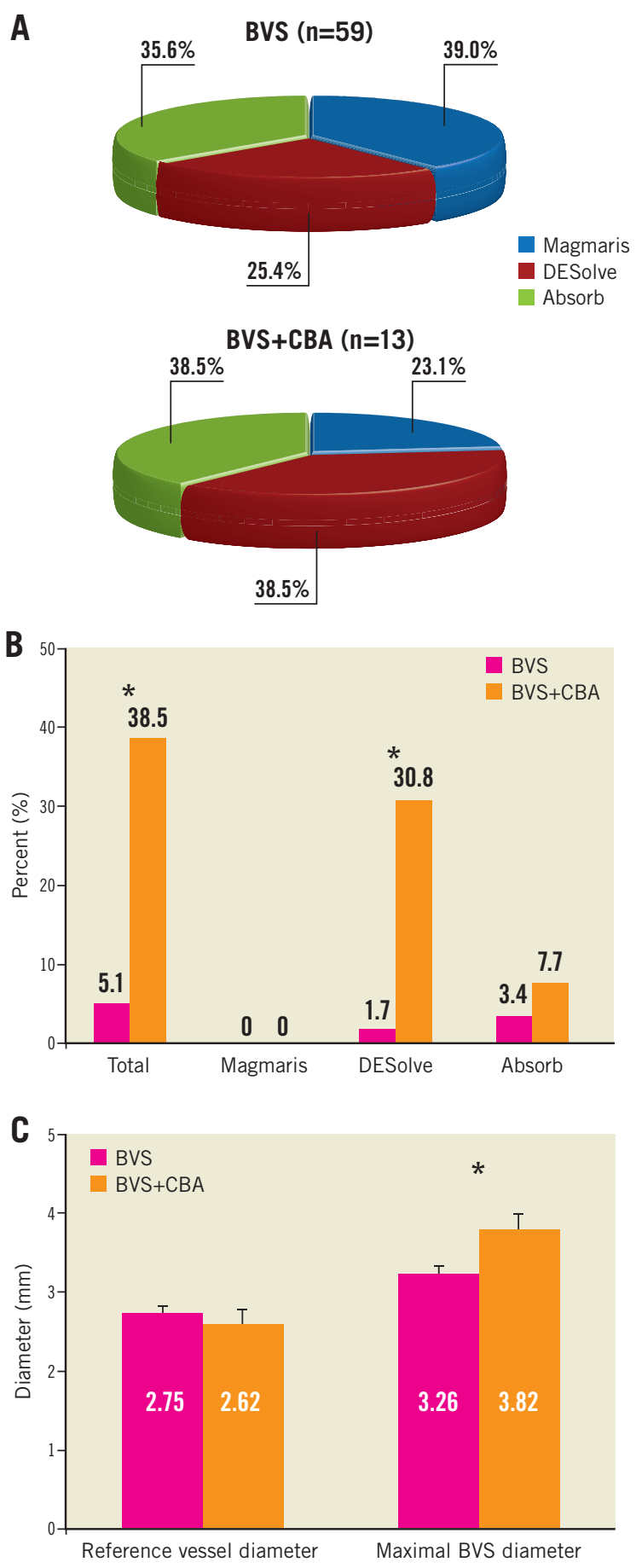

Figure 1. Coronary aneurysm formation following scaffold implantation. A) Distribution of BVS. B) Frequency of coronary aneurysms in the absence or presence of $C B A . C$ ) Mean reference vessel diameter and maximal BVS diameter per quantitative coronary angiography. ${ }^{*} p<0.05$. BVS: bioresorbable vascular scaffold; CBA: cutting balloon angioplasty; SEM: standard error of the mean 
At six months, the maximal BVS diameter and the relative vessel dilatation were significantly higher in the CBA group (conventional BVS: $3.26 \pm 0.1 \mathrm{~mm}$ versus CBA: $3.82 \pm 0.3 \mathrm{~mm}, \mathrm{p}=0.014$ for maximal BVS diameter, and $19.8 \pm 2.0 \%$ versus $54.4 \pm 14.8 \%, \mathrm{p}=0.001$ for relative vessel dilatation). Eight patients (11.1\%) with coronary aneurysm were identified by QCA, of whom 3/59 (5.1\%) patients were in the conventional BVS group (one DESolve patient with two aneurysms in two different arteries, and two Absorb patients) and 5/13 (38.5\%) patients were in the CBA group (four DESolve, one Absorb), $\mathrm{p}=0.003$. No coronary aneurysm was observed in lesions treated with the Magmaris magnesium-based scaffold (Figure 1). Figure 2 provides details of each coronary aneurysm.

\section{Discussion}

Coronary aneurysms should be avoided as they may disturb the laminar flow, have been shown to be associated with restenosis and stent thrombosis, and may lead to vessel rupture ${ }^{2-4}$. So far, coronary aneurysm formation after BVS implantation has only been described in case reports and one recent study with 90 patients treated with Absorb scaffold that found coronary aneurysms in 3\% and evaginations in $56 \%$ of patients ${ }^{2,5}$.

In our series, lesion preparation with CBA was associated with a significantly higher rate of coronary aneurysms at sixmonth follow-up ( $38.5 \%$ compared to $5.1 \%, \mathrm{p}=0.003)$. While it is understood that lesions with CBA treatment are probably

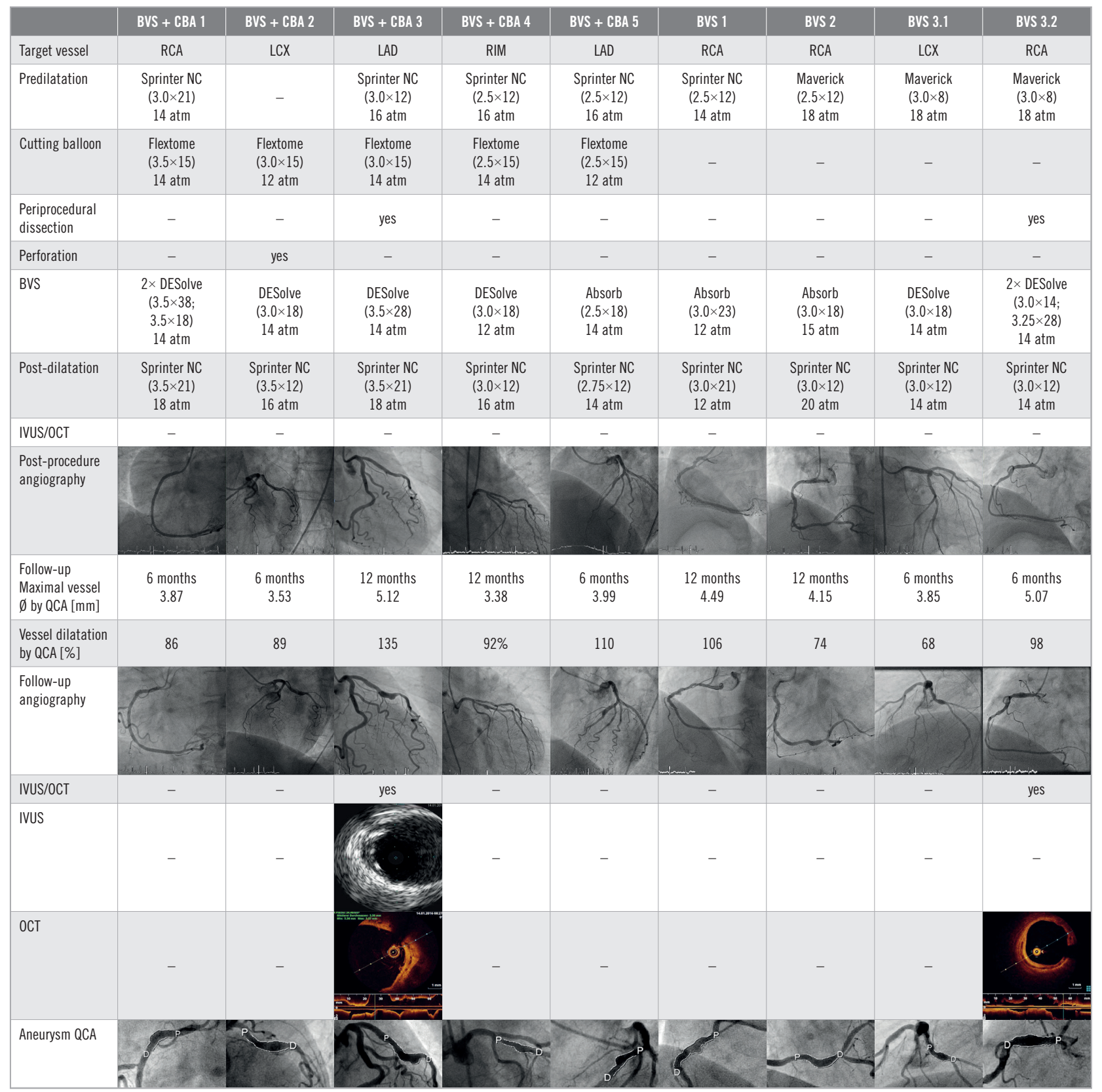

Figure 2. Details of patients with coronary aneurysms. BVS: bioresorbable vascular scaffold; CBA: cutting balloon angioplasty; RIM: ramus intermedius; SEM: standard error of the mean 
more complex, we did not see relevant differences in baseline characteristics except the gender difference. Aggressive lesion preparation with pathological vessel healing is probably the underlying key mechanism. The highest frequency of coronary aneurysms was found in the DESolve group treated with CBA $(4 / 5,80 \%)$, whereas no aneurysm was observed after implantation of the magnesium-based Magmaris scaffold. The patient numbers are too low to draw valid conclusions, but one might speculate that the early resorption of scaffold struts and material characteristics may play an important role. The metal-based Magmaris scaffold behaves similarly to a permanent DES, and in BIOSOLVE-II no malapposed struts were observed on OCT at six-month follow-up ${ }^{6}$. The relatively high number of coronary aneurysms in the DESolve group could be caused by the selfcorrecting wall apposition of this device, eventually causing vessel irritation.

\section{Study limitations}

The limitations are those of a retrospective, single-centre analysis with a limited number of patients. No systematic intravascular imaging or core laboratory assessments were performed. Therefore, our results are hypothesis-generating at best.

\section{Conclusions}

The current study suggests that lesion preparation with cutting balloon angioplasty is associated with coronary aneurysm formation in polymeric scaffold implantation. Therefore, CBA should be used with caution in this setting. Our results should be confirmed in larger multicentre trials, including OCT and core laboratory assessments.

\section{Impact on daily practice}

Our study raises a caveat and suggests that cutting balloon angioplasty for lesion preparation in combination with implantation of polymeric scaffolds should be used with caution due to a high risk of coronary aneurysm formation.

\section{Conflict of interest statement}

H. Degen is a consultant for Biotronik and Cardiac Dimensions. M. Haude is a consultant for Biotronik, OrbusNeich, and Abbott, and has received grant support from Biotronik, OrbusNeich, Abbott, Medtronic, and Cardiac Dimensions. The other authors have no conflicts of interest to declare.

\section{References}

1. Vaquerizo B, Barros A, Pujadas S, Bajo E, Estrada D, Miranda-Guardiola F, Rigla J, Jiménez M, Cinca J, Serra A. Bioresorbable everolimus-eluting vascular scaffold for the treatment of chronic total occlusions: CTO-ABSORB pilot study. EuroIntervention. 2015;11:555-63.

2. Gori T, Jansen T, Weissner M, Foin N, Wenzel P, Schulz E, Cook S, Münzel T. Coronary evaginations and peri-scaffold aneurysms following implantation of bioresorbable scaffolds: incidence, outcome, and optical coherence tomography analysis of possible mechanisms. Eur Heart J. 2016;37:2040-9.

3. Pahlavan PS, Niroomand F. Coronary artery aneurysm: a review. Clin Cardiol. 2006;29:439-43.

4. Alfonso F, Pérez-Vizcayno MJ, Ruiz M, Suárez A, Cazares M, Hernández R, Escaned J, Bañuelos C, Jiménez-Quevedo $P$, Macaya C. Coronary aneurysms after drug-eluting stent implantation: clinical, angiographic, and intravascular ultrasound findings. J Am Coll Cardiol. 2009;53:2053-60.

5. Nakatani S, Ishibashi Y, Suwannasom P, Grundeken MJ, Høj Christiansen E, Onuma Y, Serruys PW; ABSORB Cohort B Investigators. Development and receding of a coronary artery aneurysm after implantation of a fully bioresorbable scaffold. Circulation. 2015;131:764-7.

6. Haude $\mathrm{M}$, Ince $\mathrm{H}$, Abizaid A, Toelg R, Lemos PA, von Birgelen C, Christiansen EH, Wijns W, Neumann FJ, Kaiser C, Eeckhout E, Lim ST, Escaned J, Garcia-Garcia HM, Waksman R. Safety and performance of the second-generation drug-eluting absorbable metal scaffold in patients with de-novo coronary artery lesions (BIOSOLVE-II): 6 month results of a prospective, multicentre, non-randomised, first-in-man trial. Lancet. 2016;387:31-9. 